Ethics in the Anthropocene: Traumatic Exhaustion and Posthuman Regeneration in N. K. Jemisin's Broken Earth Trilogy

María Ferrández San Miguel

University of Zaragoza

mfsm@unizar.es; ORCID Id: http://orcid.org/0000-0003-4402-0815

Word count: 8,206 words. 


\title{
Ethics in the Anthropocene: Traumatic Exhaustion and Posthuman Regeneration in N. K. Jemisin's Broken Earth Trilogy
}

\begin{abstract}
This article focuses on N. K. Jemisin's triple-Hugo-award-winning epic trilogy Broken Earth (2015-2017), using the strategically powerful perspectives of trauma studies and the discourses around the figure of the posthuman, and paying special attention to issues of ethics and the notion of the Anthropocene. It is contended that the main issues at play in the Broken Earth trilogy are the representation of structural oppression against a marginalized minority and the foregrounding of the possible consequences of extreme exploitation of the environment. The article argues that Jemisin's work draws a connection between the subjugation and exploitation of certain groups and of nature, framing both as traumatic phenomena. Yet, the story allows for a possibility of regeneration in the promotion of a posthuman form of ethics. In short, as this article attempts to prove, the Broken Earth series considers the past, interprets the present and offers a cautionary tale about a the future that makes a strong case for the hopeful practice of posthuman ethics.
\end{abstract}

Keywords: N. K. Jemisin; Broken Earth; trauma theory; the posthuman; the anthopocene; posthuman ethics

Funding details: The writing of this article has been funded by the Spanish Ministry of Economy and Competitiveness (FFI2015-63506).

Disclosure statement: No potential conflict of interest

“Don't be patient. Don't ever be.

This is the way a new world begins".

- N. K. Jemisin, The Stone Sky

\section{Introduction}

The creation of new, alternative worlds has, for the most part, been the province of speculative fiction. World-building is, indeed, an essential aspect of genre fiction, and 
one that often determines its commercial success. Critical recognition and enduring cultural influence, however, arguably depend on the power of a novel or series to invite readers to see "the world anew and to engage responsibly in the creation of better futures". ${ }^{1}$ What Mark Bould and Sherryl Vint are alluding to in this quotation, and what N. K. Jemisin's words in the epigraph metafictionally suggest, is the political potential of speculative fiction. Literature that dwells on the realm of the fantastic challenges the fixity of the dominant social order by imagining alternative worlds that nevertheless evoke reality and refract the familiar, ${ }^{2}$ the better to highlight both the provisional character of the present and the contingency of the future. This creates a space for social criticism and resistance, ${ }^{3}$ and also, interestingly, opens up the genre to various critical inquiries. ${ }^{4}$

This article focuses on N. K. Jemisin's triple-Hugo-award-winning epic trilogy Broken Earth (2015-2017), using the strategically powerful perspectives of trauma studies and the discourses around the figure of the posthuman, and paying special attention to issues of ethics and the notion of the Anthropocene. Although it is still a rather new critical pursuit, a number of critics have, in the last few years, pointed to an imbrication of the paradigms of trauma and posthumanity and begun to explore their influence on present understandings of human existence as represented by contemporary fiction, generating new discursive practices. $^{5}$

While science fiction has been the privileged genre for most critics of posthuman theory, fantasy literature and other speculative genres have tended to be disregarded in

\footnotetext{
${ }^{1}$ Bould and Vint, 111.

${ }^{2}$ Graham, 57

${ }^{3}$ See Jackson and Graham.

${ }^{4}$ Edward James and Farah Mendlesohn, 3

${ }^{5}$ See Luckhurst, Collado-Rodríguez and Ferrández San Miguel; see also Braidotti, "Critical Posthumanities," 10, 20.
} 
discussions and theorizations of the posthuman, probably owing to the former's deep investments in notions of technoscience and its general grounding in the scientifically possible. Trauma theory, for its part, has completely ignored the realm of the fantastic, presumably because, as Roger Luckhurst argues, "there have been prescriptive tendencies around what is considered to be an appropriate aesthetics for the representation of trauma". ${ }^{6}$ Furthermore, it is undeniable that trauma studies has from the start been "suspicious of the investment in narrative pleasure often equated with mass cultural forms". ${ }^{7}$

Since their establishment as autonomous fields of study in the last decades of the $20^{\text {th }}$ century, trauma theory and the discourses around the posthuman figuration have become key frameworks for the study of contemporary culture and its artifacts, reaching the status of critical paradigms that have dramatically transformed a number of discursive practices and disciplines. In its focus on the wound, trauma studies explores how psychological trauma affects individual or collective consciousness, and revolves around the epistemological and ontological crises of being that it generates. As for the discourse of the posthuman, it is concerned with a redefinition of the category of the human and its Others and with the disruption of the dichotomies that have been built around them since the Enlightenment. As I have argued elsewhere, at the core of the discourses on both trauma and the posthuman lies an exploration of the relationship between human and Other. From the perspective of trauma, the Other represents a threat to the individual's subjectivity and stability. Furthermore, as we will see, otherness is a central concept for some models of trauma, such as postcolonial trauma theory, which focuses on the

\footnotetext{
${ }^{6}$ Luckhurst, "Future Shock," 159.

${ }^{7}$ Ibid.
} 
experiences of non-Western or minority cultures by exploring the traumatizing potential of insidious exposure to structural oppression and violence. ${ }^{8}$ From the perspective of the posthuman, the encounter with the Other entails the recognition and assimilation of the trace of the Other within the self. This leads to hybridization and to the transformation of human subjectivity, which is often articulated as empowering and liberating. ${ }^{9}$ The combination of these two frameworks for the analysis of literary texts responds, on the one hand, to calls by some trauma critics about the need to "de-provincializ[e] trauma" by joining trauma studies with other methodologies of inquiry in order to extend its analytical and theoretical scope, ${ }^{10}$ and on the other hand, it addresses the emphasis on the part of a number of theorists of the posthuman on the interdisciplinarity of what has been termed "critical posthumanities". ${ }^{11}$ This article responds to both calls by approaching N. K. Jemisin's Broken Earth series.

Straddling several speculative genres, ${ }^{12}$ The Broken Earth trilogy-The Fifth Season (TFS), The Obelisk Gate (TOG) and The Stone Sky (TSS) — is set on what at first

\footnotetext{
${ }^{8}$ See Craps, Postcolonial Witnessing, and Root.
}

${ }^{9} \mathrm{Cf}$. Braidotti, Posthuman. Because of the prevalent association of the posthuman with issues of technoscience both in popular culture and in criticism, posthuman theories have tended to emphasize, as Stacy Alaimo argues, "a techno-futurism that melds human and machine, often focusing on information systems" (159). However, many theorists of the posthuman, such as Hawaway and Graham, privilege instead the strand that focuses on hybridity, which deals with posthumanism "as a Foucaldian type of social discourse" (Åsberg, 189) that recognizes "the material interrelatedness of all beings" (Alaimo, 151; see also Braidotti, Posthuman).

${ }^{10}$ Rothberg, xiv; see also Luckhurst, "Beyond Trauma."

${ }^{11}$ Braidotti, "Critical Posthumanities," Posthuman; see also Åsberg.

${ }^{12}$ What at first seems to be classic fantasy soon reveals itself to show features of scifi, the Gothic/horror and clifi, as the analysis will show. 
appears to be a pre-technological (alternative) Earth under constant threat of apocalypse as a result of extreme seismic activity, which periodically triggers so-called 'fifth seasons'. These seasons are large-scale environmental alterations that can last for centuries and dramatically transform the world and all its life forms, including humanity. Those who manage to survive attempt to rebuild civilization by joining together in 'comms', multi-racial sociopolitical units within the Imperial governance system in which members are assigned or born into one of the seven use-castes-Breeders, Innovators, Resistants, Strongbacks, Leadership, Cutters and Hunters. Among the enduring survivors are 'orogenes', individuals who possess the ability to use thermal and kinetic forms of energy to address seismic activity thanks to an overdeveloped sensory organ called 'sessapinae'. Despite their obvious usefulness in a world like the Stillness, orogenes - disparagingly called 'roggas', a "dehumanizing word for someone who has been made into a thing" their comms, or taken to the 'Fulcrum' - an institution for the training and taming of orogenes for the common good, among other things - where they are placed under the control and supposed protection of a 'guardian'. Guardians owe their exceptional power and longevity to an implant that allows them to use the power of the Earth, but forces them to obey its will. Indeed, the Earth - Father Earth — is shown in the trilogy to have a will of its own, which is directed towards the goal of destroying humanity as a way of avenging a previous civilization's extreme exploitation and ravaging of natural resources. Appeasing Father Earth, and so ending the seasons in the hopes of saving humanity, becomes the duty of the protagonist, Essun, an orogene woman who is on a quest to find her daughter Nassun after the murder of her other orogene child at the hands of her own

\footnotetext{
${ }^{13}$ Jemisin, TFS, 140.
} 
husband. The extremely powerful little girl is, however, determined to become Father Earth's tool to destroy human life forever, which brings mother and daughter face to face at the end of the series.

As this condensed summary suggests, the main issues at play in the Broken Earth trilogy are the representation of structural oppression against a marginalized minority, on the one hand, and the foregrounding of the possible consequences of extreme exploitation of the environment, on the other. It is my contention that Jemisin's work draws a connection between the subjugation and exploitation of certain groups (racism and coloniality) and of nature (the Anthropocene), framing both as traumatic phenomena. Yet, the story allows for a possibility of regeneration in the figuration of the posthuman being and the promotion of a posthuman form of ethics. In short, as this article attempts to prove, the Broken Earth series considers the past, interprets the present and offers a cautionary tale about a the future that makes a strong case for the hopeful practice of posthuman ethics.

\section{Traumatic Exhaustion}

As its name aptly foretells, the Broken Earth trilogy confronts readers with a world that is physically and socially ruined, exhausted. The inhabitants of the Stillness live under the constant threat of a natural disaster that may finally succeed in wiping out civilization from the face of the Earth. Yet, as we will see, as the brutal narrative of structural exploitation and violence against the oppressed orogene minority progresses, one cannot help but wonder — with some of the main characters — whether there might be worlds that simply deserve to burn: "some worlds are built on a fault line of pain, held up by nightmares. Don't lament when those worlds fall. Rage that they were built doomed in 
the first place". ${ }^{14}$ The first book of the series, The Fifth Season, literally opens with the end of the world: "a personal ending"" on the one hand — the end of Essun's world as she finds her baby son's body on the floor of her house, beaten to death by her non-orogene husband after he had discovered the secret of otherness that his family had been hiding; on the other, the end of the world "writ continentally"16 — as a result of a cataclysm purposefully caused by Alabaster, supposedly the most powerful orogene alive, in order to unleash the titular fifth season that will eventually destroy civilization, and thus free "his fellow slaves", ${ }^{17}$ even if it can be only in death.

One of Dominick LaCapra's most influential contributions to the framework of trauma theory has been the drawing of a differentiation between what he terms "structural trauma" and "historical trauma". ${ }^{18}$ In Writing History, Writing Trauma (2001), LaCapra defines structural trauma as related to "transhistorical absence (absence of/at the origin) [which] appears in different ways in all societies and all lives". ${ }^{19}$ Among other sources, structural trauma in LaCapra's theorization results from the realization of our intrinsic mortality. ${ }^{20}$ Historical trauma, on the contrary, is construed as "specific, and not everyone is subject to it or entitled to the subject position associated with it", ${ }^{21}$ and "is related to particular events ... such as the Shoah or the dropping of the atom bomb on Japanese

\footnotetext{
${ }^{14}$ Jemisin, TSS, 7.

${ }^{15}$ Jemisin, TFS, 1.

${ }^{16}$ Ibid.

${ }^{17}$ Ibid., 6.

${ }^{18}$ LaCapra, Writing History, 76-86.

${ }^{19}$ Ibid., 76-77.

${ }^{20}$ Ibid., 77.

${ }^{21}$ Ibid., 78.
} 
cities". ${ }^{22}$ LaCapra's distinction is particularly apt for the social and environmental exhaustion that the Broken Earth series stages.

In Jemisin's world, existence is determined by the structural trauma of the absence of the figuration of the earth as Eden, as nurturing mother. This results from a previous civilization's boundless environmental exploitation:

\begin{abstract}
According to legend, Father Earth did not originally hate life. In fact, as the lorists tell it, once upon a time Earth did everything he could to facilitate the strange emergence of life on his surface. He crafted even, predictable seasons; kept changes of wind and wave and temperature slow enough that every living being could adapt, evolve; summoned waters that purified themselves, skies that always cleared after a storm. ... Then people began to do horrible things to Father Earth. They poisoned waters beyond even his ability to cleanse, and killed much of the other life that lived on his surface. They drilled through the crust of his skin, past the blood of his mantle, to get at the sweet marrow of his bones. ${ }^{23}$
\end{abstract}

In other words, "where [humans] should have seen a living being, they saw only another thing to exploit. Where they should have asked, or left alone, they raped". ${ }^{24}$ Despite the trilogy's fictional setting, these quotations undoubtedly have a disquieting resonance for $21^{\text {st }}$-century readers. It is increasingly agreed that we have now entered the so-called age of the Anthropocene, an epoch that is defined by "human-induced climatic, biological, and geological transformations of our planet". ${ }^{25}$ As Rosi Braidotti explains, this stresses "both the technologically mediated power acquired by anthropos and its potentially lethal consequences for everyone else". ${ }^{26}$ Jemisin's trilogy resorts to the fantastic to invite

\footnotetext{
${ }^{22}$ Ibid., 80.

${ }^{23}$ Jemisin, TFS, 379.

${ }^{24}$ Jemisin, TSS, 247-48.

${ }^{25}$ Åsberg, 187.

${ }^{26}$ Braidotti, Posthuman, 66 (emphasis in the original).
} 
readers to imagine the potential aftermath of our recklessly exploitative attitude towards the environment and its limited resources.

As such, the trilogy depicts the worst case scenario of post-anthopocentrism and geo-centrism. The Earth, no longer the passive victim of humanity's mastery and abuse, is presented as having a will of its own and a vengeful nature: "The Earth did not start this cycle of hostilities. ... It did not start this war, but it will rusting well have. Its. Due". ${ }^{27}$ Such an understanding is backed by the posthuman concept of material agency. As Stacy Alaimo explains, attributing agency to the environment is still problematic. ${ }^{28}$ After all, agency has been, since the Enlightenment, the exclusive attribute, and a defining feature, of the human, relegating animal and earth Others to the realms of the instinctual and the deterministic respectively. Yet, Alaimo notes, "the evacuation of agency from nature underwrites the transformation of the world into a passive repository of resources for human use". ${ }^{29}$ As Donna Haraway aptly emphasizes, "who and what counts as an actor ... matter[s] for political, ethical and emotional action". ${ }^{30}$ Therefore, Jemisin's decision to attribute will and agency to "Father Earth" may be read as a political move in itself, which works to undermine the tenets under which humanism and anthropocentrism were built, an issue that will be taken up in the following section. Indeed, as a result of Father Earth's violent seismic activity, human society and activity have been reduced to collective attempts to survive in the context of structural trauma, and every single effort is directed towards the goal of remaining alive as a species. It is worth adding that the word "survive" and its derivatives appear in countless occasions in the trilogy.

\footnotetext{
${ }^{27}$ Jemisin, TSS, 248 (emphasis in the original).

${ }^{28}$ Alaimo, 143.

${ }^{29}$ Ibid., 143.

${ }^{30}$ Haraway, Companion Species Manifesto, 27.
} 
There is a collective within the Stillness, however, for whom survival means something entirely different. For orogenes, staying alive entails being enslaved, dehumanized and oppressed. In the six interspersed chapters within The Stone Sky that describe the rise and fall of the lost civilization of Syl Anagist and narrate the events that led to the start of the seasons, orogenes are revealed to be the descendants of a group of genetically modified beings who were created from the so-called "Niess" people with an exploitative purpose in mind: to be used as tools, more specifically to tune the so-called "Plutonic Engine", an instrument designed to channel the power of the Earth, and so to "establish an energetic cycle of infinite efficiency". ${ }^{31}$ As such, the first orogenes were considered objects, a possession of the empire, and not supposed to show emotions or desires — or have them, for that matter. Present-day orogenes have inherited this system of structural oppression in the name of the survival of humanity: "ferals" are often killed by their comms when discovered, normally as children; if they are 'lucky' to be found first by Imperial agents, they are placed under the supervision of a Guardian and taken to the Fulcrum, where they receive training to boost their usefulness against Father Earth's whims and are broken into obedience:

\footnotetext{
"Crazy" is also what roggas who obey choose to call roggas that don't. You obeyed, once, because you thought it would make you safe. He showed you-again and again, unrelentingly, he would not let you pretend otherwise - that if obedience did not make one safe from the Guardians or the nodes or the lynchings or the breeding or the disrespect, then what was the point? The game was too rigged to bother playing. ${ }^{32}$
}

Perhaps the most horrific materialization of the exploitation of orogenes is the existence

\footnotetext{
${ }^{31}$ Jemisin, TSS, 97.

${ }^{32}$ Jemisin, TOG, 159.
} 
of the so-called node network, which provides seismic stillness for the wealthiest and most densely populated areas of the supercontinent. Some orogene children, those who cannot learn control or who are deemed too powerful to be allowed to live to adulthood, are placed in one of the network's outposts, where they are kept in a zombie-like statustheir consciousness cancelled and their bodily functions mechanically attended to - and are plugged into the system so that their instinctual orogeny automatically quell seismic activity. In short, as the narrator puts it, "someone must suffer, if the rest are to enjoy luxury". 33

Suffer is, indeed, what the main characters do. As the discussion so far has made clear, life for orogenes is presented in the novel as profoundly traumatic. In the case of Essun, she endured the rejection of her family and the cruel Fulcrum training as a childincluding her Guardian's breaking of the bones in her hand to teach her to control her power; as an adult, she was required to have sexual intercourse with an appointed partner, Alabaster, to breed powerful orogene children that would maintain the system of Imperial orogenes; she witnessed the murder of her lover Innon and the destruction of their home and community at the hands of a Guardian, which led her to kill her own child, Coru, to avoid his capture and enslavement; ${ }^{34}$ and finally, after rebuilding her life in disguise, she loses her two new children-one murdered and the other abducted by her non-orogene husband Jija. The abducted child, Nassun, who becomes a co-protagonist and focalizer in the second and third books of the trilogy, has had to endure her mother's harsh training-

\footnotetext{
${ }^{33}$ Jemisin, TSS, 334 (emphasis in the original).

${ }^{34}$ This passage is undoubtedly inspired by Margaret Garner's life story, which reinforces the links that the series purposefully establishes between the structural oppression to which orogenes are subjected and slavery in the US, as the quotation above also suggests.
} 
which was nothing but a form of 'acting out ${ }^{35}$ of her own traumatic experiences at the Fulcrum, bone breaking included; Nassun has also had to deal with the realization that her baby brother has been murdered because of his orogeny and she will never be accepted for what she is; and finally, she is forced to kill her own father in self-defense.

Returning now to Dominick LaCapra's distinction between structural and historical trauma, the main character's traumatic experiences in the context of a system of structural violence and oppression evoke the living conditions under North-American slavery and within colonial regimes. As such, the protagonists are shown to be affected by what has been variously called 'safe-world violations', 'insidious trauma', 'oppression-based trauma', 'postcolonial syndrome', 'postcolonial stress disorder' and 'post-traumatic slavery syndrome' ${ }^{36}$ These terms constitute postcolonial clinicians and researchers' attempts to call attention to and remedy the narrow understanding of traumatic stress as resulting from a "sudden, unexpected, catastrophic event", ${ }^{37}$ which, as Stef Craps explains, "makes some important sources of trauma invisible and unknowable". ${ }^{38}$ Maria Root's concept of insidious trauma is particularly apt to approach the protagonists" exposure to "cumulative traumatic experiences" 39 : as the tragedies listed above suggest, these experiences usually owe to "the social status of an individual being devalued because a characteristic intrinsic to their identity is different from what is valued by those in power". ${ }^{40}$ She further characterizes insidious trauma as having cumulative

\footnotetext{
${ }^{35}$ LaCapra, "Trauma," 713.

${ }^{36}$ Craps, "Beyond Eurocentrism," 49.

${ }^{37}$ Ibid.

${ }^{38}$ Ibid.

${ }^{39}$ Root, 248.

${ }^{40}$ Ibid., 240.
} 
effects, affecting a community of people, and "leav[ing] a distinct threat to psychological safety, security, or survival". 41

While the protagonists do manage to survive, they certainly do not do so unscathed. The most evident result of their exposure to a structural system of violence is the splitting of their personality. In the case of Nassun, she is torn between being the good 'normal' girl that her father loves and the powerful orogene that she truly is, which has dramatic consequences for both: "the stabbing is the result of the outcome of an impossible choice he demanded of her: to be either his daughter or an orogene". ${ }^{42}$ As for Essun, she is similarly split between the drive towards assimilation through disguise and the push to embrace her true power and be her true self. In both cases, the characters' split personalities allow them to negotiate their subjection to different forms of oppression at great psychological cost. As Essun puts it as she is about to strangle her baby son Coru and tear the earth apart in an attempt to kill herself and her Guardian at the end of book one, "survival is not the same thing as living" 43 when you are not accepted within the category of the human.

Perhaps the most remarkable consequence of the main characters' subjection to structural oppression is their transformation into violent killers. Despite all their suffering, it is undeniable that Essun, Nassun and the other main characters are nothing like the exemplary victims of western collective imagination: they are neither heroic nor pathetic in their suffering, but mass murderers who allow their vast sorrow and outrage to take them over, with disastrous consequences for human life on the Stillness. Essun, for instance, overcome by panic over being recaptured by her Guardian, destroys a whole

\footnotetext{
${ }^{41}$ Ibid., 241.

${ }^{42}$ Jemisin, TSS, 30.

${ }^{43}$ Jemisin, TFS, 441.
} 
town and all its inhabitants by activating a super volcano; she ices her whole village to death when they attempt to stop her from leaving; and she throws a swarm of 'boilbugs' at the army posted at the gates of the comm that has taken her in, which slowly and painfully kills them all and renders the area inhabitable for years. As for Alabaster, as mentioned above, he starts the worst fifth season in centuries in order to put an end to the exploitation of his enslaved children, the node maintainers, which will last a thousand years and perhaps succeed in destroying humanity. Nassun also ices a whole city to escape from the Fulcrum, murders her father and, sick to the soul with grief and disgust over the way the world treats orogenes, she decides to become Father Earth's agent to wipe out humanity from the face of the Earth:

\footnotetext{
And then, in a sudden blaze of memory that Nassun has not permitted herself to see or consider for more than a year, she remembers her last day in Tirimo. ... Looking down and staring and staring and thinking What is that? and staring and thinking Is it a ball? ... the unrecognizable deflated ball-thing on the floor is Uche that is Uche he is Uche - ... Nassun drops into a crouch, then to her knees. She wants to vomit but instead she spits words onto the ground between her splayed hands. "G-g-gone! I want it all GONE, Schaffa! I want it to BURN, I want it burned up and dead and gone, gone, NOTHING l-l-left, no more hate and no more killing just nothing, $r$ rusting nothing, nothing FOREVER - ${ }^{44}$
}

It may be argued, then, that the series problematizes a simplistic attribution of the trauma categories of victim, perpetrator and bystander, emphasizing the fuzzy limits that exist between the three in the context of historical trauma. It is worth keeping in mind that, as we have seen, the 'human' inhabitants of the Stillness are victimized by the structural trauma of the absence of the Earth as nurturing mother, but many of them are also shown to be cruel perpetrators of violence against orogenes, while all may be said to be more

\footnotetext{
44 Jemisin, TSS, 89-90.
} 
than bystanders in that humans are undoubtedly beneficiaries of the system of oppression and enslavement of orogenes: "Say nothing to me of innocent bystanders, unearned suffering, heartless vengeance. When a comm builds atop a fault line, do you blame its walls when they inevitably crush the people inside? No; you blame whoever was stupid enough to think they could defy the laws of nature forever". ${ }^{45}$ Despite this problematization of the distribution of blame, the privileging in the series of the marginalized characters' perspectives at all times undoubtedly promotes reader identification, to the extent that it arguably makes one wonder, as the inevitable final confrontation between Essun and Nassun approaches, whether life on the Stillness does deserve saving, and whether there is any hope of regeneration.

\section{Posthuman Regeneration}

N. K. Jemisin's answer to the questions above comes at the end of the third book of the trilogy: Nassun is determined to destroy human life forever, which will kill her too, and Essun fights her to try and save her daughter's life. Realizing that the confrontation will destroy them both, Essun sacrifices her own life so that her daughter may have a chance to live. Moved by her mother's final act of love, Nassun decides to give up her determination and uses her power to reach a truce with Father Earth and put an end to the fifth seasons. The question that this ending raises, then, is whether, against all odds, the Broken Earth trilogy might be said to put forward a humanist message, as happens in countless disaster cultural products where the values of humanism stand amid all the postapocalyptic ruin. ${ }^{46}$ Nassun does save humanity in the end; but Essun, transformed by her

\footnotetext{
45 Jemisin, TSS, 7.

${ }^{46}$ Cf. Braidotti, Posthuman, 64.
} 
stone-eater ${ }^{47}$ friend Hoa into one of his kind, conspicuously sets as her plan for eternity to make the world better, and the trilogy ends with the words that act as this article's epigraph: "Don't be patient. Don't ever be. This is the way a new world begins". ${ }^{48}$ It is my contention that, rather than simply extending the ethos of humanism, the series embraces and brings to the fore the liberating potential of the posthuman figuration, disrupts the nature/culture divide and promotes a posthuman form of ethics as the path towards regeneration.

To begin with, it is worth highlighting the fact that the Broken Earth trilogy builds a taxonomy of beings in terms of their human-ness: regular humans versus guardians, orogenes, stone eaters and Father Earth — all of them "sentient non-humans"49 of some kind. A key aspect of most of these beings' otherness is the fact that it results from human intervention. In the particular case of orogenes - and, by extension, stone eaters-, they are shown to have been genetically engineered from the Niess people, which justifies addressing the trilogy's deep investments in notions of structural violence, otherness and the definition of the human from the specific perspective of the posthuman. To illustrate my point, it is worth quoting at length from the third book of the series:

Niespeople looked different, behaved differently, were different— but every group is different from others. Differences alone are never enough to cause problems. Syl Anagist's assimilation of the world had been over for a century before I was ever made; all cities were Syl Anagist. All languages had become Sylanagistine. But there

${ }^{47}$ Stone eaters, the most mysterious non-humans of the Stillness, are revealed at the end of the series to be former super-powerful orogenes who got transformed into living statues - with their consciousness intact - as a result of their manipulation of magic, the substance of life that runs through every living being, including the Earth (TOG 361). The issue of magic and its critical significance will be taken up again presently.

${ }^{48}$ Jemisin, TSS, 398.

${ }^{49}$ Jemisin, TFS, 83. 
are none so frightened, or so strange in their fear, as conquerors. ... It became easy for scholars to build reputations and careers around the notion that Niess sessapinae were fundamentally different, somehow-more sensitive, more active, less controlled, less civilized - and that this was the source of their magical peculiarity. This was what made them not the same kind of human as everyone else. Eventually: not as human as everyone else. Finally: not human at all. Once the Niess were gone, of course, it became clear that the fabled Niess sessapinae did not exist. Sylanagistine scholars and biomagestres had plenty of prisoners to study, but try as they might, no discernible variance from ordinary people could be found. This was intolerable; more than intolerable. After all, if the Niess were just ordinary human beings, ... the world built on their inhumanity would fall apart. So... they made us. ${ }^{50}$

This is arguably one of the most conspicuous and politically-charged passages of the series. The first part of the quotation alludes to the more or less widespread scientificthough not so much popular-consensus that race is merely a social construct without biological meaning. Racial categories are increasingly perceived within the scientific community as an imprecise marker of the wealth of human diversity, since "commonly defined racial groups are genetically heterogeneous and lack clear-cut genetic boundaries". ${ }^{51}$ Another issue that this quotation puts forward is the link between the imperialist aspirations of Syl Anagist and the dehumanization of the Niess. Thus, structural oppression and violence against orogenes can be traced back to an empire's drive to conquer and dominate others. Finally, and more importantly for my purposes, the quotation above emphasizes the role of the Other as the means to negatively define identity by articulating what one is not. Sylanagistines, it appears, felt the need to emphasize the Niess's inferiority, their otherness, the better to oppress them. Thus, when Sylanagistine assumptions about the Niess's sessapinae turned out to be a fallacy, they

\footnotetext{
${ }^{50}$ Jemisin, TSS, 210-11 (emphasis in the original).

${ }^{51}$ Yudell and others, 565.
} 
felt compelled to bring them into existence through genetic engineering in order to sustain the system and project that had been built around the discourse of Niess inhumanity.

All these ideas have obvious resonance for contemporary readers. Race as is understood in our culture is not a basis for oppression or discrimination in the universe of the series. In present-day Stillness, racial differences exist, but they have no cultural correlation with social status. Of course, in the Broken Earth trilogy race has compellingly been displaced onto a different figure of otherness more suitable for the speculative genre: the posthuman being, the monster. In other words, Jemisin's future Earth is color-blind, ${ }^{52}$ but structural oppression and discrimination on the basis of a collective's otherness survive unscathed. The implication is that the need to articulate oneself against what one is not - the foundation of subjectivity in Western philosophyand the drive to oppress the Other have little to do with physical traits and run deep within the human psyche. Jemisin puts it best in her website: "in the case of the Broken Earth trilogy, personhood matters". 53

In her influential book on the representations of the posthuman, Elaine Graham cogently explains that one of the ways in which the boundaries between the human and

${ }^{52}$ As Alondra Nelson explains, that racial distinctions and, by extension, racial discrimination would be eliminated from the future by technological advances was the founding fiction of the digital age (1). This myth was eagerly endorsed and spread by science fiction literature from the 1950s onwards, which depicted a color-blind future in which humanity had managed to leave behind racial conflict (Bould, 177). A number of African American voices have sought to expose the misguidedness of such a fantasy by producing alternative stories about culture, technology and the future. Their work has been termed "Afrofuturism", described by Mark Dery as "speculative fiction that treats African-American themes and addresses African-American concerns in the context of $20^{\text {th }}$-century technoculture-and, more generally, African-American signification that appropriates images of technology and a prosthetically enhanced future" (qtd. in Bould, 182).

53 Jemisin, “Creating Races,” N. pag. 
its Others have been traditionally established is through the discourse of monstrosity, ${ }^{54}$ claiming that "the ascription of monstrous and subhuman traits serv[es] to rationalize xenophobia and prejudice". ${ }^{55}$ It is worth pointing out that the word "monster" appears repeatedly in the three books of the series to refer to all the non-human beings. Orogenes, stone eaters and guardians are not only considered, and generally treated, as monsters due to the consensus built around their non-human condition, but they have internalized their own monstrosity. In both cases, monstrosity crops up from the fact that these beings are "awful and aweful" from the contradictions of their embeddedness in power relations: they yield immense power and they are simultaneously displaced to the margins of society because of their non-human condition.

As a result of this embeddedness in power, however, these posthuman beings threaten what Graham calls the "ontological hygiene" by which Western culture has drawn the limits that separate humans, animals, machines and nature, ${ }^{57}$ since they decenter the notion of the human and draw attention to the fact that, as Braidotti explains, this concept "never was a universal or a neutral term to begin with. It is rather a normative category that indexes access to privileges and entitlements. Appeals to the 'human' are always discriminatory: they create structural distinctions and inequalities among different categories of humans, let alone between humans and non-humans". ${ }^{58}$ The Broken Earth

\footnotetext{
${ }^{54}$ Graham, 12.

${ }^{55}$ Ibid., 53.

${ }^{56}$ Ibid.

${ }^{57}$ Ibid., 11.

${ }^{58}$ Braidotti, "Critical Posthumanities," 5.
} 
trilogy is, thus, peopled by a wealth of posthuman beings that radically expose and threaten key dualisms of the Western philosophical tradition.

One of the posthuman monsters to most powerfully haunt and threaten Western cultural imagination was Mary Shelley's Frankenstein. As Graham explains, the monster's physical grotesqueness evokes horror and disgust, while his voice and human sensibilities, his ambition to be part of human culture and learning challenge his nonhuman status. ${ }^{59}$ Similarly, in her seminal essay "A Cyborg Manifesto", Donna Haraway famously introduces the concept of the cyborg as "a cybernetic organism, a hybrid of machine and organism, a creature of social reality as well as a creature of fiction" ${ }^{\prime 60}$ whose existence derives from the dissolution of four traditional boundaries: human vs. animal, organic vs. machinic, physical vs. non-physical and self vs. other. ${ }^{61}$ These figures of hybridity embody the liberatory potential of the posthuman subject, which offers a way out of "the maze of dualisms in which we have explained our bodies and our tools to ourselves". ${ }^{2}$

More specifically, the Broken Earth trilogy and its posthuman subjects dissolve one of the founding dualisms of modern thought: the nature/culture divide. This divide, which establishes the two categories as clearly delineated and mutually exclusive, is by no means apolitical; it is rooted in, and legitimates, power relations and has often been a tool to justify and enforce oppression and discrimination against a collective, as feminist and postcolonial critics have been tirelessly denouncing for years. In The Companion Species Manifesto (2003), which emphasizes humanity's co-habitation and, hence, co-

\footnotetext{
${ }^{59}$ Graham, 64-65.

${ }^{60}$ Haraway, Simians, Cyborgs and Women, 149.

${ }^{61}$ Ibid., 151-153.

${ }^{62}$ Ibid., 181.
} 
evolution with other species, Haraway puts forward the concept of 'naturecultures', ontologies of living where nature and culture cannot be separated and where the notion of human nature is replaced by a naturecultures continuum. This notion emphasizes the interconnection and inseparability of nature and culture in terms of ecological relations, which emerge from social and biophysical forces. Speaking also from the perspective of animal studies, Cary Wolfe similarly emphasizes the connection of human and nonhuman forms of life, their constitutive co-dependency and finitude and their mutual entanglement with notions of technology and vulnerability. ${ }^{63}$

Evoking such theorizations, in the universe of the Stillness 'regular' humans are shown to be natural creatures by emphasizing their mortality, embodiment and embeddedness in the physical world and by the reduction of all intellectual pursuit to the instinctual, natural act of surviving as a species. On the other hand, a key point of the series - arguably its very founding notion — is the idea that Jemisin's non-human Others, these hybrid beings who have been repeatedly dehumanized and excluded from the entitlements of the human, are cultural creatures, 'persons': “they have never believed us human, but we will prove by our actions today that we are more than tools. Even if we aren't human, we are people. They will never be able to deny us this again". ${ }^{64}$ This renders the nature/culture divide that has long supported Western philosophy unsustainable in the trilogy. In Jemisin's post-Anthropocene Earth, characterized as it is by the vengeful retaliation of a willful Father Earth as a result of previous boundless exploitation of natural resources on the part of humans, by orogenes' genetically engineered ability to control seismic activity, by Guardians' prosthetically enhanced capacity to use the force

\footnotetext{
${ }^{63}$ Worlfe, 66, 74.

${ }^{64}$ Jemisin, TSS, 329 (emphasis in the original).
} 
of the environment and by stone eaters' power to merge with and move through the substance of the Earth, nature is shown to be no longer separable from culture.

As a number of prominent critics of the posthuman have noted, strong ethical and political possibilities emerge from the profound sense of entanglement between nature and culture. Donna Haraway may be credited with being among the first to direct our attention towards a new model of posthuman ethics that stresses the importance of reconsidering the relationships between humans, non-human animals, techno-others (i.e. cyborgs) and the environment (1991, 2003, 2008). As she puts it, in naturecultures, "to be one is always to become with many" 65 and "all the actors become who they are in the dance of relating". ${ }^{66}$ Cary Wolfe similarly argues for a model of posthuman ethics that challenges liberal humanism and its reliance on the concept of rights, whereby "ethical standing and civic inclusion are predicated on rationality, autonomy and agency", ${ }^{67}$ and that rests instead on a recognition of human and non-human constitutive co-dependency. Speaking from the 'new materialist' perspective, Stacy Alaimo compellingly advocates a form of posthuman environmentalist ethics "that is not circumscribed by the human but is instead accountable to a material world that is never merely an external place but always the very substance of our selves and others". ${ }^{68}$ Indeed, in Bodily Natures (2010), she puts forward the concept of 'trans-corporeality', which she defines as "a recognition that one's bodily substance is vitally connected to the broader environment". ${ }^{69}$ Finally, recognizing also the irreducibility of difference, Rosi Braidotti calls for an ethics based on the primacy

\footnotetext{
${ }^{65}$ Haraway, When Species Meet, 4.

${ }^{66}$ Ibid., 25 (emphasis in the original).

${ }^{67}$ Wolfe, 127.

${ }^{68}$ Alaimo, 158.

${ }^{69}$ Ibid., 63.
} 
and transversality of relations, on interdependence, ${ }^{70}$ and grounds it on the recognition of what she terms 'zoe', "the non-human, vital force of Life", 71 "the transversal entity that allows us to think across previously segregated species, categories and domains", ${ }^{72}$ All these different but complementary theories of a posthuman ethics are similarly grounded on the belief that human activities and practices are not only intermeshed with the wider world and its non-human- and earth-others, but also accountable to them.

Backed by these groundbreaking notions, the Broken Earth trilogy enacts a powerful posthuman ethics in that the human is shown to be inevitably entangled and interconnected with the Other. First and foremost, through the concept of 'magic', which may be claimed to be the literal materialization of Braidotti's notion of 'zoe':
Magic derives from life - that which is alive, or was alive, or even that which was alive so many ages ago that it has turned into something else. All at once this understanding causes something to shift in your perception, and ... [y]ou see it suddenly: the network. A web of silver threads interlacing the land, permeating rock and even the magma just underneath, strung like jewels between forests and fossilized corals and pools of oil. Carried through the air on the webs of leaping spiderlings. Threads in the clouds, though thin, strung between microscopic living things in water droplets. ${ }^{73}$

The use of the word 'network' in this passage is particularly conspicuous, since it evokes the notions of interdependence and kinship. As is widely agreed within disciplines as varied as sociology, economics, biology or computer science, the main consequence of interdependence is that what affects one also impacts the other, and the other way round. Secondly, there is the case of stone eaters, where the material quality of the earth has been

\footnotetext{
${ }^{70}$ Braidotti, Posthuman, 95.

${ }^{71}$ Ibid., 60.

${ }^{72}$ Braidotti, "Critical Posthumanities," 12.

${ }^{73}$ Jemisin, TOG, 361 (emphasis in the original).
} 
transferred from the natural world to human bodies, rendering these beings a paradigmatic trope of Alaimo's notion of trans-corporeality. Finally, a sense of entanglement is further supported in the trilogy by means of the fictional organ called 'sessapinae': presumably inspired by the popular belief that animals are able to sense a natural disaster right before it strikes, this organ allows humans and non-humans in the trilogy-i.e. orogenes and Guardians, but also animals — alike to 'sess' changes in the earth with varying degrees of awareness and accuracy. In short, in Jemisin's universe, the attention of the readers is directed towards the interconnection and constitutive co-dependency of all living entities, which is then presented as the necessary basis for ethical and political response. As the narrator puts it at the very beginning of the second book of the series, "after all, a person is herself, and others. Relationships chisel the final shape of one's being. I am me, and you", 74

\section{Conclusion}

As I hope my analysis has proved, Jemisin's trilogy holds considerable potential to become an imaginative testing ground for critical thought. The Broken Earth trilogy addresses the structural trauma of the loss of the Earth as Eden and the historical trauma of structural oppression and violence on the basis of a collective's otherness. More importantly, the series draws a connection between coloniality and the Anthopocenebetween the enslavement of a group of beings and the exploitation of natural resources: just as the ethos of coloniality is based on denying a collective, in this case orogenes, the status of humans and the rights and entitlements attached to that subject position, and just as it establishes a system of oppression and discrimination around this collective's alleged

\footnotetext{
${ }^{74}$ Jemisin, TOG, 1.
} 
inhumanity, this logic also marginalizes the environment into the position of an object that can be exploited, which as we well know leads to ecological crisis, i.e. the Anthropocene. Indeed, both forms of exploitation are shown in the series to result from, and are ideologically sustained by, the articulation of non-human beings as inhuman Others, which has catastrophic consequences for both the individual and the collective. The trilogy, thus, deals with human responsibility and accountability for the oppression of the Other and for the anthropogenic transformations of the environment.

Amid all its dystopian and post-apocalyptic pessimism, the Broken Earth trilogy also leaves some room for hope. Jemisin raises pertinent questions about the constitution and reconfiguration of the (post)human Other and its boundaries, the relationship between culture and the natural world, the agency of nature and the nature of matter. As we have seen, the representation of the posthuman being challenges the anthropocentric division of the world into human and Other and undermines the nature-culture divide. As a result of the emphasis on human beings' interconnection and constitutive interdependency with other non-human or more-than-human entities, the category of the human is displaced and shown to be "always already othered". ${ }^{75}$ Finally, the series calls for a posthuman form of ethics grounded on entanglement as the path towards regeneration.

To conclude, N. K. Jemisin's triple-Hugo-award-winning trilogy creates a link between cultural imagination and ethical and political positions. As Hilary Rose brilliantly puts it, "through the creation of extravagantly fictitious worlds in which everyday reality becomes strange, there emerges the possibility of dreaming of (or having nightmares about) different and other futures, of writing new myths which will enable us

\footnotetext{
${ }^{75}$ Nayar, 23.
} 
to take a part in shaping our futures". ${ }^{76}$ The conventions of speculative fiction have enabled for Jemisin a compelling posthuman and environmentalist experiment of the imagination which has the potential to inspire readers to reflect on the status quo. I am firmly convinced, with N. K. Jemisin, that literature is not merely a reflection of reality, but a tool to give it shape: as she brilliantly claimed in her historic Hugo acceptance speech, "creators are the engineers of possibility". ${ }^{77}$ It is in the readers' hands to respond to Jemisin's invitation to engage in the construction of new, and hopefully, better worlds.

\section{References}

Alaimo, Stacy. Bodily Natures: Science, Environment, and the Material Self. Bloomington, IN/Indianapolis: Indiana University Press, 2010.

Åsberg, Cecilia. "Feminist Posthumanities in the Anthropocene: Forays into the Postnatural.” Journal of Posthuman Studies 1, no. 2 (2017): 185-204.

Bould, Mark. "The Ships Landed Long Ago: Afrofuturism and Black SF." In “Afrofuturism,” special issue, Science Fiction Studies 34, no. 2 (July 2007): 17786.

Bould, Mark, and Sherry Vint. "Political Readings." In The Cambridge Companion to Fantasy Literature, ed. Edward James and Farah Mendlesohn, 102-11. Cambridge: Cambridge University Press, 2012.

Braidotti, Rosi. The Posthuman. Oxford: Polity, 2013.

\footnotetext{
76 qtd. in Graham, 59.

${ }^{77}$ Cunningham, N. pag.
} 
-. "A Theoretical Framework for the Critical Posthumanities." In "Transversal Posthumanities," eds. Matthew Fuller and Rosi Braidotti, special issue, Theory, Culture \& Society. (May 2018): 1-31

Collado-Rodríguez, Francisco. "Intratextuality, Trauma, and the Posthuman in Thomas Pynchon's Bleeding Edge." Critique: Studies in Contemporary Fiction 57 no. 3 (2016): 229-41.

Craps, Stef. "Beyond Eurocentrism: Trauma Theory in the Global Age." In The Future of Trauma Theory, eds. Gert Buelens, Sam Durrant, and Robert Eaglestone. 4562. London and New York: Routledge, 2014.

—. Postcolonial Witnessing: Trauma Out of Bounds. New York: Palgrave MacMillan, 2013.

Cunningham, Joel. “Read N. K. Jemisin's Historic Hugo Speech.” B\&N Sci-Fi \& Fantasy Blog. Barnes \& Noble. https://www.barnesandnoble.com/blog/sci-fifantasy/read-n-k-jemisins-historic-hugo-speech/

Ferrández San Miguel, María. “Appropriated Bodies: Trauma, Biopower and the Posthuman in Octavia Butler's 'Bloodchild' and James Tiptree, Jr.'s 'The Girl Who Was Plugged In." Atlantis. Journal of the Spanish Association for AngloAmerican Studies 40, no. 2 (2018): 27-44.

Graham, Elaine. Representations of the Post/human: Monsters, Aliens and Others in Popular Culture. Manchester: Manchester University Press, 2002.

Haraway, Donna. The Companion Species Manifesto: Dogs, People, and Significant Otherness. Chicago: Prickly Paradigm, 2003.

—. Simians, Cyborgs and Women: The Reinvention of Nature. London and New York: Routledge, 1991.

—. When Species Meet. Minneapolis: University of Minnesota Press, 2008. 
Jackson, Rosemary. Fantasy: The Literature of Subversion. London and New York: Routledge, 2015. First published 1981.

James, Edward, and Farah Mendlesohn, eds. Introduction to The Cambridge Companion to Fantasy Literature, 1-4. Cambridge: Cambridge University Press, 2012.

Jemisin, N. K. “Creating Races.” N. K. Jemisin. http://nkjemisin.com/2015/08/creatingraces/

—. The Fifth Season. New York: Orbit, 2015.

—. The Obelisk Gate. New York: Orbit, 2016.

—. The Stone Sky. New York: Orbit, 2017.

LaCapra, Dominick. "Trauma, Absence, Loss.” Critical Inquiry 25, no. 4 (Summer 1999): 696-727.

—. Writing History, Writing Trauma. Baltimore: Johns Hopkins University Press, 2001. Luckhurst, Roger. "Beyond Trauma: Torturous Times." In "Beyond Trauma: The Uses of the Past in Twenty-First Century Europe," special issue, European Journal of English Studies 14, no. 1 (2010): 11-21.

—. "Future Shock." In The Future of Trauma Theory: Contemporary Literary and Cultural Criticism, ed. Robert Eaglestone, Sam Durrant and Gert Buelens, 15767. London and New York: Routledge, 2014.

Nayar, Pramod K. Posthumanism. Cambridge: Polity, 2013.

Nelson, Alondra. “AfroFuturism.” Social Text 71, no. 20 (Summer 2002): 1-15.

Root, Maria. "Reconstructing the Impact of Trauma on Personality." In Personality and Psychopathology: Feminist Reappraisals, eds. Laura S. Brown and Mary Ballou, 229-65. New York: Guilford, 1992.

Rothberg, Michael. "Preface: Beyond Tancred and Clorinda-Trauma Studies for Implicated Subjects." In The Future of Trauma Theory, eds. Gert Buelens, Sam 
Durrant, and Robert Eaglestone, xi-xviii. London and New York: Routledge, 2014.

Shelley, Mary. Frankenstein: Or the Modern Prometheus. London: Penguin Books, 2003.

Wolfe, Cary. What is Posthumanism? Minneapolis: University of Minnesota Press, 2010.

Yudell, Michael, Dorothy Roberts, Rob DeSalle, and Sarah Tishkoff. "Taking Race out of Human Genetics: Engaging a Century-Long Debate about the Role of Race in Science.” Science Magazine, February 5, 2016: 564-65. 